Pacific Journal of Mathematic 


\title{
COMMUTANTS OF SOME QUASI-HAUSDORFF MATRICES
}

\author{
B. E. RHOADES
}

Let $B(c)$ denote the Banach algebra of bounded linear operators over $c$, the space of convergent sequences, and $\Gamma^{*}$ the subalgebra of conservative infinite matrices. Given an upper triangular matrix $A$ in $\Gamma^{*}$, a sufficient condition is established for the commutant of $A$ in $\Gamma^{*}$ to be upper triangular. Also determined is the commutant, in $B(c)$, of certain quasi-Hausdorff matrices.

The spaces of bounded, convergent and null sequences will be denoted by $m, c, c_{0}$ respectively, and $l$ will denote the set of sequences $x$ satisfying $\sum_{k}\left|x_{k}\right|<\infty$. Let $\Delta^{*}$ denote the algebra of conservative upper triangular matrices; i.e., $A \in \Delta^{*}$ implies $A: c \rightarrow c$ and $a_{n k}=0$ for $n>k$. $\mathscr{H}^{*}$ will denote the algebra of conservative quasiHausdorff transformations, and $\Gamma$ the algebra of all conservative matrices. $\Gamma_{a}^{1^{*}}$ is the quasi-Hausdorff transformation generated by $\mu_{n}=a(n+a)^{-1}, a>1$. For other specialized terminology the reader can consult [3] or [5].

One cannot answer commutant questions for upper or lower triangular matrices in $B(c)$ by taking transposes. For example, let $C$ denote the Cesàro matrix of order $1 . C^{T}$ is not conservative. On the other hand, the matrix $A=\left(a_{n k}\right)$ defined by

$$
a_{n k}=\left\{\begin{array}{l}
1 \text { for } n=\left(\begin{array}{c}
j+1 \\
2
\end{array}\right),\left(\begin{array}{l}
j \\
2
\end{array}\right)+1 \leqq k \leqq n ; \quad j=1,2, \cdots, \\
0 \text { otherwise },
\end{array}\right.
$$

is conservative, but $A^{T}$ is not. It is true that the transpose of any conservative quasi-Hausdorff matrix is a conservative Hausdorff matrix. $C$ shows that the converse is false.

We begin with some results analogous to those of [3] and [5].

THEOREM 1. Let $A \in \Delta^{*}$. If $A$ has the property that

(1) for each $t \in m, n \geqq 0,\left(A-a_{n n} I\right) t=0$ implies $t \in$ linear span $\left\{e^{0}, e^{1}, \cdots, e^{n}\right\}$, then every matrix $B$ with finite norm which commutes with $A$ is upper triangular.

$B \leftrightarrow A$ implies

$$
\sum_{j=0}^{k} b_{n j} a_{j k}=\sum_{j=n}^{\infty} a_{n j} b_{j k} ; \quad n, k=0,1,2, \cdots
$$

Set $k=0$ to get

$$
b_{n 0} a_{00}=\sum_{j=n}^{\infty} a_{n j} b_{j 0} ; \quad n=0,1,2, \cdots
$$


which can be written in the form $\left(A-a_{00} I\right) t^{0}=0$, where $t^{0}=\left\{b_{n 0}\right\}_{n=0}^{\infty}$. By hypothesis, $t$ belongs to the linear span of $e^{0}$, so that $b_{n 0}=0$ for all $n>0$. By induction one can show that $b_{n k}$ for all $n>k$ and $B$ is upper triangular.

Remarks. 1. The condition that $A$ be conservative is not needed in the proof. All one needs are restrictions on $A$ and $B$ sufficient to guarantee that the summations in (2) exist for each $n$ and $k$; for example, it would be sufficient to assume that each row of $A$ is in $l$ and each column of $B$ is in $m$.

2. It is an open question whether condition (1) is necessary. (The proof of the necessity of Theorem 1 in [3] is faulty, because it fails to show that $B$ has finite norm.)

An upper triangular matrix is called factorable if $a_{n k}=c_{n} d_{k}, n \leqq k$. Examples of upper triangular factorable matrices in $B(c)$ are the transposes of the weighted mean methods $\left(\bar{N}, p_{n}\right)$ with $p_{n}=a^{n}, a>1$, and the $\Gamma_{a}^{1^{*}}, a>1$.

THEOREM 2. If $A$ is a factorable upper triangular matrix with $a_{n n} \neq 0$ for all $n$, then $B \leftrightarrow A$ implies $B$ is upper triangular.

Proof. Set $n=k=0$ in (2) to get $\sum_{j=1}^{\infty} a_{0 j} b_{j 0}=0$. From (2) with $k=0, n=1$, we have

$$
b_{10} a_{00}=\sum_{j=1}^{\infty} a_{1 j} b_{j 0}=\frac{c_{1}}{c_{0}} \sum_{j=1}^{\infty} a_{0 j} b_{j 0}=0 .
$$

Since $a_{00} \neq 0, b_{10}=0$. By induction, $b_{n 0}=0$ for all $n>0$. Then by induction on $k$, we can show $b_{n k}=0$ for all $n>k$, and $B$ is upper triangular.

Corollary 1. If $A \in \Delta^{*}, A$ is factorable and has exactly one zero on the main diagonal, then $B \leftrightarrow A$ implies $B$ is upper triangular.

Proof. Let $N$ be such that $a_{N N}=0$. If $N>0$, then the proof of Theorem 2 forces $b_{n k}=0$ for $n>k, k<N$. For $n>N, k=N$ in (1) we have

$$
\sum_{j=n}^{\infty} a_{n j} b_{j N}=\sum_{j=0}^{N} b_{n j} a_{j N}=b_{n N} a_{N N}=0,
$$

or, $-a_{n n} b_{n N}=\sum_{j=n+1}^{\infty} a_{n j} b_{j N}$; i.e., $-d_{n} b_{n N}=\sum_{j=n+1}^{\infty} b_{j N} d_{j}$, which leads to $d_{n} b_{n N}=0$. Since $d_{n} \neq 0, b_{n N}=0$. By induction, $b_{n k}=0$ for $n>k>N$.

Corollary 2. If $A \in \Delta^{*}$, is factorable, and has at least two 
nonadjacent zeros on the main diagonal, then there exists a matrix $B \leftrightarrow A, B$ not upper triangular.

Let $M$ and $N$ satisfy $a_{M M}=a_{N N}=0, N>M+1$. There are four possibilities: (i) $c_{M}=c_{N}=0$, (ii) $c_{M}=d_{N}=0$, (iii) $d_{M}=c_{N}=0$, and (iv) $d_{M}=d_{N}=0$.

If $d_{N} \neq 0$ the system (1) with $n=M$ has the solution $t_{k}=0$, $k>N, t_{N}=1, t_{M}=0, t_{k}=-\sum_{j=k+1}^{N} a_{k j} t_{j} / a_{k k}, k \neq M, k<N$. If $d_{N}=0$, then (1), with $n=M$, has the solution $t_{k}=0, k>N, t_{N}=1, t_{N-1}=0$, $t_{M}=0$,

$$
t_{K}=-\sum_{j=k+1}^{N-1} a_{k j} t_{j} / a_{k k}, \quad k \neq M, \quad k<N-1 .
$$

Define $B$ by $b_{n M}=t_{n}, b_{n, m+1}=-c_{M} t_{n} / c_{M+1}, n \leqq N, b_{n k}=0$ otherwise. Then $B \leftrightarrow A, B \in \Gamma$, but $B \notin \Delta^{*}$.

Suppose $A \in \Delta^{*}$, is factorable, and satisfies $a_{N N}=a_{N+1, N+1}=0$, $a_{n n} \neq 0$ for $n \neq N, N+1$. If $d_{N+1}=0$ or $c_{N}=0$, then an examination of the proof of Corollary 2 shows that we can find a matrix $B$ which commutes with $A$ and which is not upper triangular. If, however, $c_{N+1}=d_{N}=0$, but $c_{N} d_{N+1} \neq 0$, then $B$ must be upper triangular.

CoRollary 3. Let $A$ be a factorable upper triangular matrix such that, for some integer $N, d_{N}=c_{N+1}=0$, and $c_{N} d_{N+1} \neq 0$, and $a_{n n} \neq 0$ for $n \neq N, N+1$. Then $B \leftrightarrow A$ implies $B$ is upper triangular.

From the proof of Theorem 2, $b_{n k}=0$ for each $k\langle N, n\rangle k$. For $k=N, n \geqq N$, we have, from (2),

$$
\sum_{j=n}^{\infty} a_{n j} b_{j N}=\sum_{j=0}^{N} b_{n j} a_{j N}=b_{n N} a_{N N}=0 .
$$

For $n>N+1$, (3) becomes $c_{n} \sum_{j=n}^{\infty} d_{j} b_{j N}=0$, which leads to $b_{n N}=0$ since $c_{n}, d_{n} \neq 0$. With $n=N$, (3) now becomes $a_{N N} b_{N N}+a_{N, N+1} b_{N+1, N}=0$. By induction it can be shown that $b_{n k}=0$ for $n>k>N+1$, so that $B$ is upper triangular.

To determine the commutants of various quasi-Hausdorff matrices in the algebras $\Delta^{*}, \Gamma$ and $B(c)$, we shall use $\Gamma_{a}^{1^{*}}$, which is a member of $\Delta^{*}$.

Corollary 4. $\operatorname{Com}\left(\Gamma_{a}^{1^{*}}\right)$ in $\Delta^{*}=\operatorname{Com}\left(\Gamma_{a}^{1^{*}}\right)$ in $\Gamma=\mathscr{H}^{*}$.

The first equality follows from Theorem 2 , since $\Gamma_{a}^{1^{*}}$ is factorable. The second equality comes from the following Lemma and Theorem 4.1 of [2]. 
LEMMA. Let $H$ be a quasi-Hausdorff method with distinct diagonal entries, $B$ any upper triangular matrix, $B \leftrightarrow H$. Then $B$ is quasi-Hausdorff.

Proof. From (2) we get

$$
\sum_{j=n}^{k} h_{n j} b_{j k}=\sum_{j=n}^{k} b_{n j} h_{j k}, \quad k \geqq n .
$$

Denote the diagonal entries of $B$ by $\lambda_{n}$. Then, it can be shown by induction that $b_{n, n+p}=\left(\begin{array}{c}n+p \\ p\end{array}\right) \Delta^{p} \lambda_{n}, p=0,1, \cdots$, and $B$ is quasiHausdorff.

Leviatan [2] has shown that every matrix which commutes formally with the inverse of $C^{T}$ is a quasi-Hausdorff matrix.

For any $T \in B(c)$ one can define continuous linear functionals $\chi$ and $\chi_{i}$ by $\chi(T)=\lim T e-\Sigma_{k} \lim \left(T e^{k}\right)$ and $\chi_{i}(T)=(T e)_{i}-\Sigma_{k}\left(T e^{k}\right)_{i}$, $i=1,2, \cdots$. Any $T \in B(c)$ has the representation $T x=v \lim x+B x$ for each $x \in c$, where $B$ is the matrix representation of the restriction of $T$ to $c_{0}$, and $v$ is the bounded sequence $v=\left\{\chi_{i}(T)\right\}$. (See, e.g. [1].)

THEOREM 3. For each $a>1$, Com $\left(\Gamma_{a}^{1^{*}}\right)$ in $B(c)=\left\{T \in B(c): v=v_{1} e\right.$ and $\left.B \in \mathscr{H}^{*}\right\}$.

Proof. From Corollary 1 of [5] we must have $A v=\chi(A) v$. Therefore, for each $n, \sum_{k=n}^{\infty} h_{n k}^{*} v_{k}=a v_{n} /(a-1)$. But

$$
h_{n k}^{*}=\frac{a k ! \Gamma(n+a)}{n ! \Gamma(k+a+1)} .
$$

Thus

$$
v_{n}=\frac{(a-1) \Gamma(n+a)}{n !} \sum_{k=n}^{\infty} \frac{k ! v_{k}}{\Gamma(k+a+1)},
$$

which leads to $v_{n}=v_{1}$ for all $n>1$.

That $B \in \mathscr{H}^{*}$ comes from the lemma.

Theorems 3 and 4 of [5] are not extendable to upper triangular matrices because the system of equations $A v=\chi(A) v$ is now much more complicated.

It is an open question whether having distinct diagonal entries is a sufficient condition for a conservative quasi-Hausdorff matrix $H^{*}$ to have the same commutant in $\Delta^{*}$ and $\Gamma$.

Acknowledgements. 1. To Professor W. Meyer-König who, after hearing a presentation of [3] and [5], requested that I consider the question of commutants for quasi-Hausdorff matrices. 
2. To the referee, for his careful reading of the original version of the paper, and for his comments, which are incorporated in Corollaries 2 and 3, and Remark 2.

\section{REFERENCES}

1. H. I. Brown, D. R. Kerr, and H. H. Stratton, The structure of $B[c]$ and extensions of the concept of conull matrix, Proc. Amer. Math. Soc., 22 (1969), 7-14.

2. D. Leviatan, Moment problems and quasi-Hausdorff transformations, Canad. Math. Bull., 11 (1968), 225-236.

3. B. E. Rhoades, Commutants of some Hausdorff matrices, Pacific J. Math., 42 (1972), $715-719$.

4. Commutants of some Hausdorff matrices, corrections, to appear in the Pacific J. Math.

5. B. E. Rhoades and A. Wilansky, Some commutants in $B(c)$ which are almost matrices, Pacific J. Math., 42 (1973), 211-217.

Received January 8, 1973.

INDIANA UNIVERSITY 



\section{PACIFIC JOURNAL OF MATHEMATICS}

EDITORS

RICHARD ARens (Managing Editor)

University of California

Los Angeles, California 90024

\section{R. A. Beaumont}

University of Washington

Seattle. Washington 98105

\section{J. DugundjI}

Department of Mathematics University of Southern California Los Angeles, California 90007

D. Gilbarg and J. Milgram

Stanford University

Stanford. California 94305

\section{ASSOCIATE EDITORS}
E. F. BECKENBACH
B. H. NEUMANN
F. WOLF
K. Yoshida

\section{SUPPORTING INSTITUTIONS}

\author{
UNIVERSITY OF BRITISH COLUMBIA \\ CALIFORNIA INSTITUTE OF TECHNOLOGY \\ UNIVERSITY OF CALIFORNIA \\ MONTANA STATE UNIVERSITY \\ UNIVERSITY OF NEVADA \\ NEW MEXICO STATE UNIVERSITY \\ OREGON STATE UNIVERSITY \\ UNIVERSITY OF OREGON \\ OSAKA UNIVERSITY
}

\author{
UNIVERSITY OF SOUTHERN CALIFORNIA \\ STANFORD UNIVERSITY \\ UNIVERSITY OF TOKYO \\ UNIVERSITY OF UTAH \\ WASHINGTON STATE UNIVERSITY \\ UNIVERSITY OF WASHINGTON

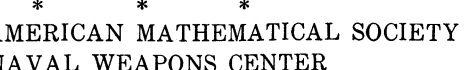

The Supporting Institutions listed above contribute to the cost of publication of this Journal, but they are not owners or publishers and have no responsibility for its content or policies.

Mathematical papers intended for publication in the Pacific Journal of Mathematics should be in typed form or offset-reproduced, (not dittoed), double spaced with large margins. Underline Greek letters in red, German in green, and script in blue. The first paragraph or two must be capable of being used separately as a synopsis of the entire paper. Items of the bibliography should not be cited there unless absolutely necessary, in which case they must be identified by author and Journal, rather than by item number. Manuscripts, in duplicate if possible, may be sent to any one of the four editors. Please classify according to the scheme of Math. Rev. Index to Vol. 39. All other communications to the editors should be addressed to the managing editor, or Elaine Barth, University of California, Los Angeles, California, 90024.

100 reprints are provided free for each article, only if page charges have been substantially paid Additional copies may be obtained at cost in multiples of 50 .

The Pacific of Journal Mathematics is issued monthly as of January 1966. Regular subscription rate: $\$ 72.00$ a year (6 Vols., 12 issues). Special rate: $\$ 36.00$ a year to individual members of supporting institutions.

Subscriptions, orders for back numbers, and changes of address should be sent to Pacific Journal of Mathematics, 103 Highland Boulevard, Berkeley, California, 94708.

\section{PUBLISHED BY PACIFIC JOURNAL OF MATHEMATICS, A NON-PROFIT CORPORATION}

Printed at Kokusai Bunken Insatsusha (International Academic Printing Co., Ltd.), 270, 3-chome Totsuka-cho. Shinjuku-ku, Tokyo 160. Japan.

Copyright (C) 1973 by Pacific Journal of Mathematics Manufactured and first issued in Japan 


\section{Pacific Journal of Mathematics}

\section{Vol. 52, No. $2 \quad$ February, 1974}

Harm Bart, Spectral properties of locally holomorphic vector-valued functions .....

J. Adrian (John) Bondy and Robert Louis Hemminger, Reconstructing infinite

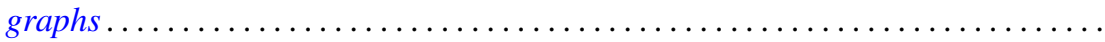

Bryan Edmund Cain and Richard J. Tondra, Biholomorphic approximation of planar

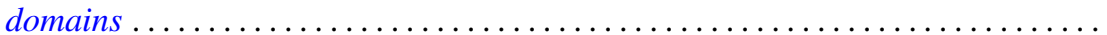

Richard Carey and Joel David Pincus, Eigenvalues of seminormal operators,

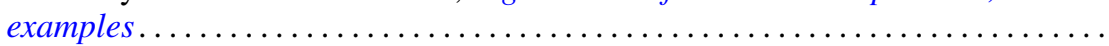

Tyrone Duncan, Absolute continuity for abstract Wiener spaces . . . . . . . . . . . . Joe Wayne Fisher and Louis Halle Rowen, An embedding of semiprime

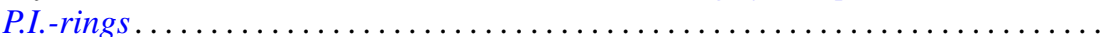

Andrew S. Geue, Precompact and collectively semi-precompact sets of semi-precompact continuous linear operators. . . . . . . . . . . . . . . .

Charles Lemuel Hagopian, Locally homeomorphic $\lambda$ connected plane continua ..... . Darald Joe Hartfiel, A study of convex sets of stochastic matrices induced by

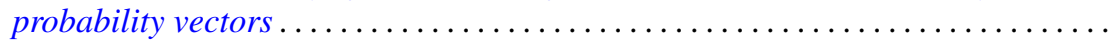

Yasunori Ishibashi, Some remarks on high order derivations $\ldots \ldots \ldots \ldots \ldots \ldots \ldots$ Donald Gordon James, Orthogonal groups of dyadic unimodular quadratic forms.

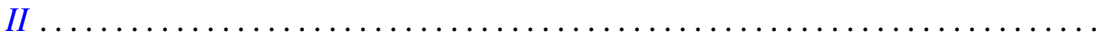

Geoffrey Thomas Jones, Projective pseudo-complemented semilattices . . . . . . . . . Darrell Conley Kent, Kelly Denis McKennon, G. Richardson and M. Schroder,

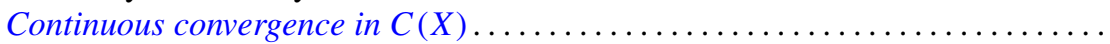

J. J. Koliha, Some convergence theorems in Banach algebras ...

Tsang Hai Kuo, Projections in the spaces of bounded linear oper

George Berry Leeman, Jr., A local estimate for typically real functions . .

475

Andrew Guy Markoe, A characterization of normal analytic spaces by the

homological codimension of the structure sheaf .........

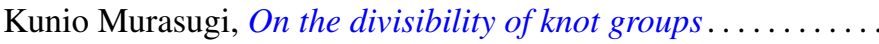

John Phillips, Perturbations of type I von Neumann algebras.

Billy E. Rhoades, Commutants of some quasi-Hausdorff matrices . .

David W. Roeder, Category theory applied to Pontryagin duality

Maxwell Alexander Rosenlicht, The nonminimality of the differential closure .

Peter Michael Rosenthal, On an inversion theorem for the general Mehler-Fock transform pair.

Alan Saleski, Stopping times for Bernoulli automorphisms

John Herman Scheuneman, Fundamental groups of compact complete locally affine complex surfaces. II. ........................

Vashishtha Narayan Singh, Reproducing kernels and operators with a cyclic vector. I. .

Peggy Strait, On the maximum and minimum of partial sums of random variables.

J. L. Brenner, Maximal ideals in the near ring of polynomials modulo 2 .

Ernst Gabor Straus, Remark on the preceding paper: "Ideals in near rings of polynomials over a field" ..........................

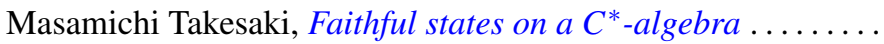

R. Michael Tanner, Some content maximizing properties of the regular simplex.

Andrew Bao-hwa Wang, An analogue of the Paley-Wiener theorem for certain

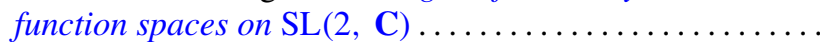

